\title{
Elastographic and echotextural characteristics of foetal lungs and liver during the final 5 days of intrauterine development in dogs
}

${ }^{a}$ Department of Animal Reproduction, Faculdade de Ciências Agrárias e Veterinárias - UNESP, Av. Prof. Paulo Donato Castellane S/N, 14884-900, Jaboticabal, SP, Brazil

b Universidade Federal do Recôncavo da Bahia, Rua Rui Barbosa 710, 44380-000, Cruz das Almas, BA, Brazil

${ }^{\mathrm{c}}$ Department of Veterinary Clinical and Surgery, Faculdade de Ciências Agrárias e Veterinárias - UNESP, Av. Prof. Paulo Donato Castellane S/N, 14884-900, Jaboticabal, SP, Brazil

d Ontario Veterinary College, University of Guelph, 50 Stone Road E, Guelph, ON, Canada

e Faculdade de Medicina Veterinária e Zootecnia da, Universidade de São Paulo, USP, Av. Prof. Dr. Orlando Marques de Paiva, 87, 05508 270, SP, Brazil

\section{A R T I C L E I N F O}

\section{Keywords:}

Canine

Foetal

Development

Elastography

Ultrasonography

\begin{abstract}
A B S T R A C T
Objective was to evaluate the echotexture and characteristics during terminal development of canine foetal respiratory and hepatic systems through elastographic examinations. Fifteen pregnant bitches were evaluated by ultrasonography twice daily, from the 53rd gestational day until whelping, and images obtained from 120 to $0 \mathrm{~h}$ before parturition were analysed. Images of foetal lungs and liver were recorded and then used for computer-assisted analyses to determine quantitative attributes. Acoustic Radiation Force Impulse (ARFI) elastographic of internal organs were classified as 'soft' (white areas) or 'hard' (dark areas) and quantitative analyses determined the mean shear wave velocities (SWV) of foetal lungs and liver. After delivery, canine neonates were clinically evaluated, and their health status was monitored weekly until 60 days postpartum. Sonographic parameters over time were compared by ANOVA and Pearson's correlations were used to determine associations between SWVs and echotextural variables. Foetal lungs and liver had a homogeneous echotexture and pulmonary parenchyma appeared hyperechoic when compared with that of the liver. Mean numerical pixel values (NPVs) of lungs decreased from 120 to $24 \mathrm{~h}$ and subsequently increased until parturition $(P=0.04)$. Lungs and liver mean $( \pm \mathrm{SD})$ SWVs $(0.98 \pm 0.12$ and $0.84 \pm 0.11 \mathrm{~m} / \mathrm{s}$, respectively) didn't vary $(P>0.05)$ over time. Fluctuations in pulmonary NPVs indicated there was a pattern corresponding to structural and functional changes that occur during the terminal stage of pre-natal canine development and hence can be a useful diagnostic tool in veterinary. Foetal lung and liver SWVs were relatively consistent and there was no detectable changes during the pre-partum period for this variable or in echotexture.
\end{abstract}

\footnotetext{
* Corresponding author at: via de acesso Prof. Paulo Donato Castellane s/n, 14884-900, Jaboticabal, São Paulo, Brazil.

E-mail address: marcusfeliciano@yahoo.com.br (M.A. Rossi Feliciano).
} 


\section{Introduction}

Prematurely born neonates frequently suffer from developmental disorders of the pulmonary system associated with relatively greater mortality rates (Rades et al., 2004) owing to respiratory distress syndrome (RDS; Martin and Fanaroff, 2013). When there is unassisted birth of puppies with RDS, there is a reported mortality rate of $25 \%$ and $25 \%$ of live puppies develop bronchopulmonary dysplasia (Cornfield, 2013).

Silva et al., (2015) reported the L/S (lecithin to sphingomyelin) ratio in the amniotic fluid and found that this ratio correlates with lung maturity and neonatal health status, with a low ratio indicating compromised respiratory function and requiring intensive care in the immediate neonatal period. In general, the underdevelopment of either pulmonary or hepatic tissues leads to a functional impairment in respiration and metabolism (Martin and Fanaroff, 2013).

The histological development of dog lungs has been amply described (Sipriani et al., 2009) and was divided into the pseudoglandular (between 35th-48th days of gestation), canalicular (from gestational days 49-56), saccular (from 57th-60th day of gestation), and alveolar phases, occurring during early post-natal life. During the canalicular phase, the appearance of pneumocytes begin the final stage of the development and maturation, culminating in surfactant production. The RDS is caused by the underproduction of surfactant due to the immaturity of type II pneumocytes, which results in inadequate function of the immature alveoli.

Pulmonary ultrasonography has the potential as a viable and non-invasive technique, for estimating the maturation of foetal human lungs (Beck et al., 2015; Serizawa and Maeda, 2010). Campbell (1969) validated the foetal parietal diameter as an indirect indicator of lung maturity and ultrasonographic evaluation of lung echo in humans and comparing it to the hepatic echotexture has yielded highly promising results for the clinical monitoring of foetal lung development and the prediction of the onset of neonatal RDS (Serizawa and Maeda, 2010; Beck et al., 2015). Shah and Graham (1986) determined that ultrasonographically-estimated placentation grade was correlated with lung maturity, and Podobnik et al. (1996) suggested that the echotextural attributes of lungs correlated with foetal maturity. Lastly, Kim et al. (2013), using spectral Doppler sonography, determined the blood flow indices of the foetal pulmonary artery and found that some of these were indicative of the development of RDS in the neonates.

The imaging methods that have been developed specifically to evaluate the elasticity of tissues are collectively referred to as elastography and are classified, based on the source of the force that is exerted on the tissues, as acoustic radiation force impulse (ARFI) and real-time shear velocity (RSV). In addition, elastographic evaluations can be performed using a qualitative technique known as strain elastography and a quantitative technique utilising compression waves (Feliciano et al., 2015c). In veterinary medicine, the ARFI ultrasonographic technique has been used to detect various pathological changes in the canine and spleen and kidneys of cats as well as in the liver, prostate gland, and testes of dogs (Holdsworth et al., 2014; Feliciano et al., 2015a, b; Garcia et al., 2015; Maronezi et al., 2015). This technique also promises to be a valid method of assessing structural changes in foetal lungs and liver that may be indicative of the maturation; previous studies by Quarello et al. (2016) in baboons and by Zheng et al. (2016) in humans defined the normal ranges for foetal lung shear wave velocity during gestational development. There, however, have been no earlier systematic studies in humans or animal species of veterinary interest using foetal pulmonary and hepatic elastography during the prenatal period.

Based on these findings, the primary aim of the present study was to determine the echotextural and elastographic characteristics, and reference ranges for shear velocities of canine foetal lungs and liver in the last 5 days of gestation. Ultrasonographic image attributes (B-mode) were also determined for correlations between shear velocities (ARFI) of foetal pulmonary and hepatic tissues. It was hypothesised that both non-invasive techniques would provide useful information on the terminal development of foetal lungs and liver in dogs.

\section{Materials and methods}

All experimental procedures were approved by the Animal Ethic and Welfare Committee (Univ Estadual Paulista) protocol $\mathrm{N}^{\circ} 11765 / 14$. Fifteen clinically healthy, primiparous or multiparous bitches of different breeds (four Dobermann Pinschers, seven Shih-tzus, and four French Bulldogs) owned by commercial dog breeders (body weight $7.0 \pm 3.6 \mathrm{~kg}$ and age $2.5 \pm 1.2 \mathrm{years}$ ) were used in this study.

After oestrous confirmation (vaginal cytology), all animals underwent intrauterine artificial insemination (AI) with fresh semen every $24 \mathrm{~h}$ for three consecutive days (Jacomini et al., 2006).

Ultrasonographic pregnancy detection (Acuson S2000 ${ }^{\mathrm{TM}}$ ultrasonic device; Siemens ${ }^{\circledR}$, Munich, Germany equipped with a $9.0 \mathrm{MHz}$ linear transducer) was performed 2 weeks after the first AI as in a previous study by Feliciano et al. (2007). All ultrasonographic examinations were performed by one experienced ( 5 years) operator to reduce the evaluation time and stress endured by pregnant animals, and to consistently ascertain the proper development of conceptuses and their gestational age (Socha et al., 2012; Yeager et al., 1992).

Because the length of gestation in dogs is variable (between 57 and 63 days; Concannon et al., 1983), subsequent ultrasonographic evaluations of foetal lungs and liver were performed twice daily, from 53 days after the first AI (canalicular phase) until whelping (saccular phase of pulmonary development). For pregnancies with greater than or equal to three foetuses, only three different foetuses were evaluated, and in the other animals all foetuses were examined. To evaluate the same three foetuses in each pregnant bitch that had more than three conceptuses, only the two caudal foetuses (one from each uterine horn) and a foetus in the uterine body region were evaluated.

The transducer was positioned in the caudal abdominal region and all adjustable settings of the ultrasonic device (e.g., depth, gain, mechanical index and focal zones) were optimised and then left unchanged for the entire study period. Ultrasonograms 

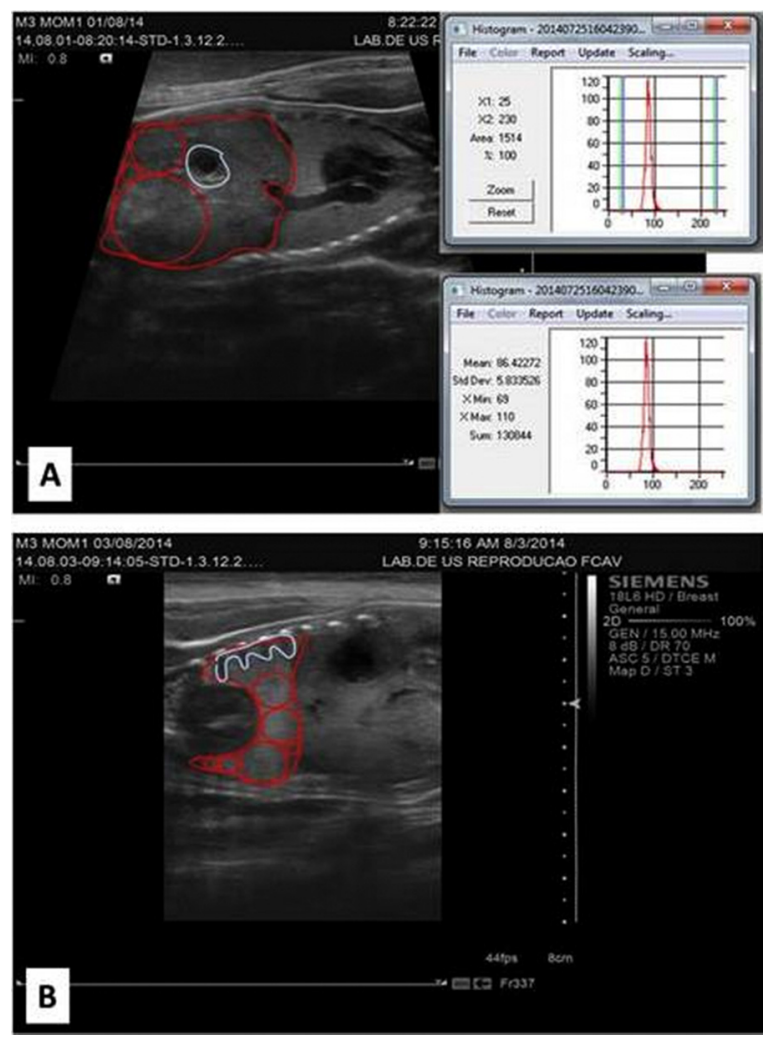

Fig. 1. Ultrasonographic images of foetal liver (A) and lungs (B) of puppies with demarcation of the cross-sectional areas of both tissues (red polygonal shape), non-parenchymal tissues or image artefacts (light blue), the region of interest spot meters placement (red circles) and histograms (right) depicting quantitative assessment of tissue echogenicity using Image ProPlus ${ }^{\circ}$ analytical software (For interpretation of the references to colour in this figure legend, the reader is referred to the web version of this article).

containing the largest cross-sectional area of foetal lungs and liver in the longitudinal plane were saved as digital images (*.jpeg format) for the subsequent computer-assisted analyses. Computerised echotextural analyses of grey-scale images were obtained using commercially available image analysis software (Image ProPlus ; Media Cybernetics Inc., San Diego, CA, USA) were assessed by a trained operator who did not know the identities of individual images and dogs. Shadowing artefacts caused by the foetal ribs and non-parenchymal tissues or large visible blood vessels were carefully avoided, and multiple, non-overlapping regions of interest (ROIs), or computer-generated circular spot meters, covering $\geq 65 \%$ of examinable ultrasonographic area of the organ were used (Fig. 1) to determine the mean, maximum and minimum numerical pixel values (NPVs) as well as the mean pixel heterogeneity (standard deviation of mean NPVs; SD-NPVs) for each animal.

Immediately after B-mode ultrasonographic examinations, the grey-scale elastographic (ARFI) sonograms of foetal lungs and liver were obtained using the commercial software, VTIQ ${ }^{\circledR}$ (Virtual Touch Tissue Quantification ; 2D-SWE technique, Siemens, Germany), previously validated for the present application by Feliciano et al. (2014). The overall quality of elastographic images was assessed by the homogeneity of the contour of each organ. Qualitative elastographic patterns were classified as 'soft' (more deformable), where most of detected areas were white, or 'hard' (less deformable), characterised by the presence of mainly dark areas, and then the patterns were compared between the lungs and the liver. Real-time quantitative elastographic attributes, or shear wave velocities ( $\mathrm{SWV} \mathrm{m} / \mathrm{s}$ ) of the tissues, were obtained using an electronic calliper $(5 \times 5 \mathrm{~mm}$; Fig. 2) placed within the parenchyma of each organ at six different locations (cranial, caudal, central, superficial, deep and medium regions), with the depth ranging from 0.5 to $2.0 \mathrm{~cm}$.

After whelping, all neonates were clinically evaluated by taking their Apgar scores (0-10; at 0, 5 and 60 min post-partum), and measuring/assessing body temperature (TC), heart rate (HR), respiratory effort (RF), gingival mucous colour, muscle tone, irritability reflexes and vocalisation (Silva, 2008). The morphophysiological development of the puppies continued during observations and weekly clinical examinations conducted until day 60 post-partum, at which time the pups were sold.

Single time point observations were compared by Student's $t$-test or one-way analysis of variance (ANOVA) using the $\mathrm{R}^{\circledR}$ statistical software (R Foundation for Statistical Computing; Vienna, Austria). Ultrasonographic data were analysed retrospectively for the period from $120 \mathrm{~h}$ to $0 \mathrm{~h}$ before whelping. All serial data were tested for heterogeneity and equal distribution using the Shapiro test and variance test, respectively, then submitted to analysis of variance (ANOVA), followed by Tukey's post-hoc test, using a randomised experimental design with the blocks represented by pregnant bitches and contrasts determined for the times of ultrasonographic examinations (hours before the parturition). Pearson's tests were used to determine correlations among echotextural and elastographic variables. The statistical significance was set at $95 \%(P$ value $<0.05)$. Results are expressed as means \pm standard 

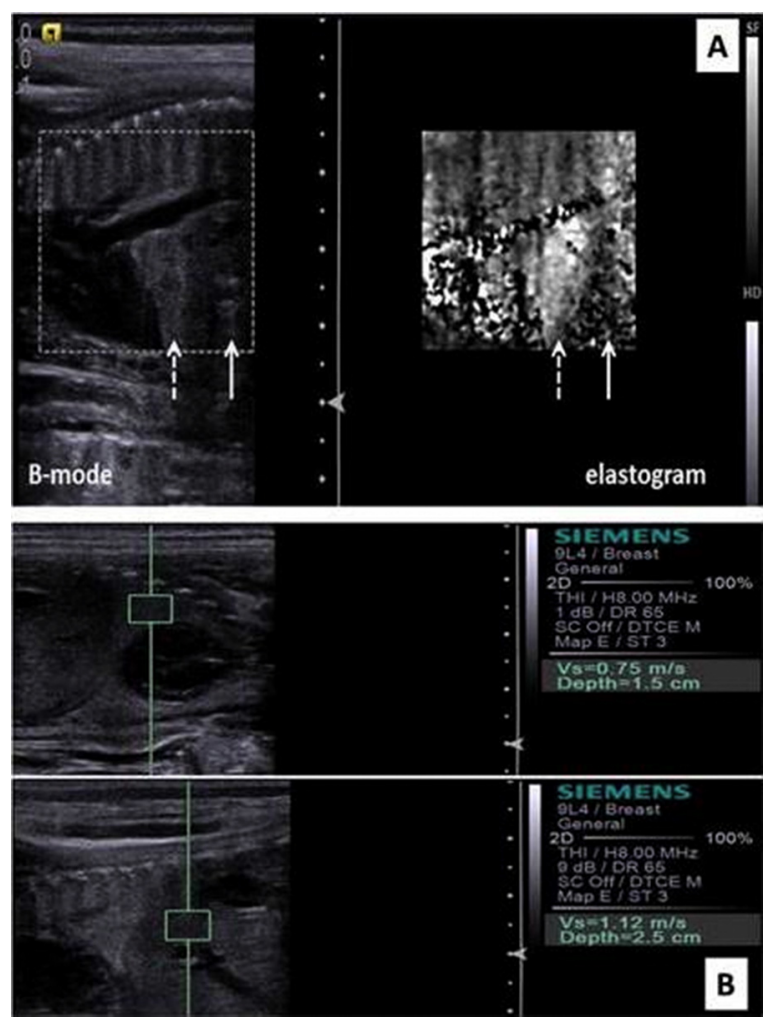

Fig. 2. (A) An ultrasonographic image and an elastogram of foetal puppy lungs (dashed arrow; light grey) and liver (continuous arrow; mid-grey); (B) quantitative elastography of pulmonary (upper panel) and hepatic (lower panel) shear velocities.

deviations (SD).

\section{Results}

Gestation length in the French Bulldog was $59.75 \pm 0.95$ days and the mean litter size was $6.75 \pm 2.21$ puppies/bitch; in the Shih-tzu, these figures were $58.85 \pm 1.21$ and $4.28 \pm 1.88$, respectively; and in the Dobermann Pinscher, $60 \pm 0.81$ and $2.5 \pm 1.29$, respectively. All animals had normal gestations and there were no apparent abnormalities in foetal or placental development detected at the time of ultrasonographic or post-partum examinations. A total of 38 new-born puppies (2.6 \pm 0.6 foetuses/bitch) were evaluated in the present study. None of these neonates had respiratory distress after birth and Apgar scores were $>7$ (Median \pm IQR: $9 \pm 1.5$ at $0 \mathrm{~min}$; $10 \pm 1.5$ at $5 \mathrm{~min}$ and $10 \pm 0.5$ at $60 \mathrm{~min}$ after birth) during the first hour of life. Ultrasonographic examinations could be performed without difficulties, and did not cause any morphophysiological alteration that was evident during clinical examinations of the puppies during the first 60 days after parturition.

All ultrasonographic (B-mode) images of the pulmonary and hepatic parenchyma obtained during the last 5 days of pregnancy in dog conceptuses had homogeneous echotexture. Both the qualitative and quantitative elastographic characteristics of the foetal lungs and liver could be determined without difficulty. Based on the qualitative elastography (Fig. 2A), foetal lungs and liver in the last $120 \mathrm{~h}$ of gestation were not deformable. The SWV of foetal lungs and hepatic tissue (Fig. 2B) did not vary during the 120-h observation period (Table 1).

Using the multiple-spot-meter technique, the average percentage of pulmonary and hepatic parenchymal tissue (i.e., ROIs within the cross-sectional area) that was subjected to quantitative echotextural analyses was $73 \pm 9 \%$ and $70 \pm 15 \%$, respectively. The NPVs (mean, minimum and maximus) of pulmonary tissue varied over the 120-h period pre-partum $(P=0.04$; Table 1$)$. The foetal lung SD-NPVs did not vary $(P>0.05)$ during the entire observation period; nor were there significant differences observed for any of the hepatic tissue characteristics. Furthermore, there were no significant correlations between SWV and echotextural characteristics for the foetal lungs and liver (Table 2).

\section{Discussion}

Based on the results from the present study, the implementation of ultrasonography and elastography of foetal lung and liver of puppies, when performed twice daily during the last 5 days of gestation, was practical, applicable and did not cause any evident clinical alterations in maternal, foetal or neonatal viability and health. This is consistent with what is known for humans (Zheng et al., 
Table 1

Summary of quantitative echotextural characteristics and shear wave velocity (SWV; $\mathrm{m} / \mathrm{s}$ ) values of canine foetal lungs and liver (mean \pm SD) measured every $12 \mathrm{~h}$ starting $120 \mathrm{~h}$ before parturition.

\begin{tabular}{|c|c|c|c|c|c|c|c|c|}
\hline \multirow[t]{2}{*}{ Hours before parturition } & \multicolumn{4}{|l|}{ Foetal lungs } & \multicolumn{4}{|l|}{ Foetal liver } \\
\hline & Mean NPVs & Min & Max & $\mathrm{SWV}(\mathrm{m} / \mathrm{s})$ & Mean NPVs & Min & Max & SWV (m/s) \\
\hline 120 & $83.8 \pm 13.0^{\mathrm{a}}$ & $58.7 \pm 11.9^{\mathrm{a}}$ & $105.6 \pm 19.4 a$ & $0.86 \pm 0.02$ & $50.5 \pm 10.7$ & $30.8 \pm 12.1$ & $75.8 \pm 15.3$ & $0.99 \pm 0.02$ \\
\hline 108 & $82.7 \pm 6.2^{\mathrm{b}}$ & $57.9 \pm 7.9^{\mathrm{ab}}$ & $103.3 \pm 16.7^{b}$ & $0.85 \pm 0.01$ & $44.0 \pm 6.4$ & $28.9 \pm 12.1$ & $68.0 \pm 14.8$ & $0.97 \pm 0.02$ \\
\hline 96 & $78.1 \pm 7.7^{\mathrm{c}}$ & $54.9 \pm 6.6^{c}$ & $98.8 \pm 9.3^{c}$ & $0.83 \pm 0.02$ & $49.2 \pm 10.5$ & $27.8 \pm 8.1$ & $77.2 \pm 14.5$ & $0.95 \pm 0.02$ \\
\hline 84 & $71.8 \pm 13.0^{\mathrm{d}}$ & $50.7 \pm 11.2^{\mathrm{d}}$ & $91.7 \pm 17.1^{\mathrm{d}}$ & $0.82 \pm 0.01$ & $54.2 \pm 9.9$ & $34.9 \pm 8.7$ & $78.3 \pm 14.7$ & $0.97 \pm 0.02$ \\
\hline 72 & $69.5 \pm 13.1^{\mathrm{e}}$ & $47.2 \pm 10.9^{\mathrm{e}}$ & $90.3 \pm 16.4^{\mathrm{e}}$ & $0.85 \pm 0.01$ & $48.2 \pm 10.9$ & $29.2 \pm 8.7$ & $71.8 \pm 16.1$ & $0.97 \pm 0.02$ \\
\hline 60 & $64.2 \pm 11.7^{\mathrm{f}}$ & $43.7 \pm 10.2^{\mathrm{f}}$ & $86.0 \pm 14.2^{\mathrm{f}}$ & $0.86 \pm 0.02$ & $41.5 \pm 6.3$ & $24.3 \pm 6.9$ & $65.7 \pm 8.7$ & $0.99 \pm 0.02$ \\
\hline 48 & $63.8 \pm 11.1^{g}$ & $41.8 \pm 10.1^{g}$ & $84.9 \pm 13.7^{g}$ & $0.85 \pm 0.02$ & $50.7 \pm 11.3$ & $30.4 \pm 8.9$ & $76.3 \pm 15.9$ & $0.99 \pm 0.02$ \\
\hline 36 & $60.8 \pm 8.8 f^{g}$ & $49.3 \pm 12.6^{g}$ & $90.4 \pm 17.1^{g}$ & $0.85 \pm 0.01$ & $48.3 \pm 12.4$ & $30.4 \pm 10.7$ & $70.4 \pm 14.5$ & $0.97 \pm 0.01$ \\
\hline 24 & $57.5 \pm 15.8^{g}$ & $37.9 \pm 14.1^{g}$ & $76.6 \pm 16.3^{g}$ & $0.82 \pm 0.02$ & $41.4 \pm 14.7$ & $24.0 \pm 12.7$ & $65.9 \pm 18.7$ & $1.02 \pm 0.01$ \\
\hline 12 & $61.3 \pm 19.7^{\mathrm{f}}$ & $43.1 \pm 16.1^{\mathrm{f}}$ & $78.0 \pm 21.9^{f}$ & $0.83 \pm 0.01$ & $44.8 \pm 12.9$ & $27.9 \pm 11.2$ & $67.1 \pm 14.9$ & $1.00 \pm 0.02$ \\
\hline 0 & $69.6 \pm 15.9^{\mathrm{e}}$ & $48.2 \pm 12.7^{\mathrm{e}}$ & $88.9 \pm 18.2^{\mathrm{e}}$ & $0.85 \pm 0.02$ & $48.7 \pm 16.9$ & $28.9 \pm 15.8$ & $72.5 \pm 21.1$ & $0.98 \pm 0.02$ \\
\hline$P$-value & $0.04^{*}$ & 0.035 & 0.035 & 0.69 & 0.16 & 0.470 & 0.520 & 0.32 \\
\hline CI 95\% & $61-83$ & $28.0-61.9$ & $62.4-108.7$ & $0.84-0.86$ & $42-51$ & $15.9-41.7$ & $53.7-92.0$ & $0.97-1.00$ \\
\hline
\end{tabular}

* Significance (ANOVA) and different letters indicating differences between the mean within a column (Tukey test); CI-confidence intervals; Min (minimum) and Max (maximum) numerical pixel values.

Table 2

Summary of correlations among shear wave velocity (SWV; $\mathrm{m} / \mathrm{s}$ ) and quantitative echotextural characteristics of canine foetal lungs and liver measured every $12 \mathrm{~h}$ starting $120 \mathrm{~h}$ before parturition.

\begin{tabular}{|c|c|c|c|c|c|c|c|c|c|c|c|}
\hline \multirow{2}{*}{\multicolumn{2}{|c|}{ Mean NPVs }} & \multirow{2}{*}{\multicolumn{2}{|c|}{$\begin{array}{l}\text { Foetal lungs } \\
\text { Min }\end{array}$}} & \multirow{2}{*}{\multicolumn{2}{|c|}{$\operatorname{Max}$}} & \multirow{3}{*}{$\begin{array}{l}\text { Mean NPVs } \\
r\end{array}$} & \multirow[b]{3}{*}{$P$} & \multicolumn{4}{|c|}{ Foetal liver } \\
\hline & & & & & & & & \multicolumn{2}{|l|}{ Min } & \multicolumn{2}{|l|}{ Max } \\
\hline$r$ & $P$ & $r$ & $P$ & $r$ & $P$ & & & $r$ & $P$ & $r$ & $P$ \\
\hline-0.190 & 0.074 & -0.200 & 0.056 & -0.167 & 0.115 & 0.181 & 0.080 & 0.160 & 0.118 & 0.196 & 0.059 \\
\hline
\end{tabular}

2016), baboons (Quarello et al., 2016) and bitches (Banzato et al., 2017) in other gestational physiology studies.

The pattern of changes we recorded in numerical pixel values (NPVs) of foetal lungs of dogs appear to reflect the structural changes that occur in lungs during the final stage of the pre-natal period. A gradual decrease in pulmonary echotexture may be associated with the termination of the canalicular phase, whereas a rapid increase in NPVs coincides with the onset and progression of the saccular phase of lung development (Sipriani et al., 2009). The canalicular phase of lung development, occurring from 12 to 3 days pre-partum, is associated with the formation of bronchioles, alveolar ducts, primitive alveoli, blood vessels, and pulmonary surfactant, as well as the establishment of the alveolar-capillary barrier and differentiation of type I and type II pneumocytes (Joshi and Kotecha, 2007). All these changes in pulmonary histophysiology may be associated with the gradual decrease in NPV values that was observed between 120 and $24 \mathrm{~h}$ before whelping in the present study; the terminal stages of growth and secretory activity of connective tissue ducts appear to be inversely related to pixel intensity of the tissue (Giffin et al., 2009, 2014). Similarly, an increase in NPVs just prior to parturition may be associated with the saccular phase of foetal lung development (Lourenço and Machado, 2013), reflecting the biochemical and functional adaptations that occur during lung maturation (Benson et al., 1983; Nicholas et al., 1986; Adler et al., 1990), specifically, the reduction in total protein content (Ahmadi et al., 2013) and augmentation of enzymatic activity (VanDuzer et al., 2014). Results of the present study, however, are inconsistent with those reported by Banzato et al. (2017), where there was an abrupt increase in pulmonary echogenicity during the canalicular phase and a plateau during the saccular phase of foetal lung development in various large dog breeds. This discrepancy may be related to the limited duration of the present study or to the size of the animals studied.

In humans, the echogenicity of foetal lungs is typically compared with that of the liver. In the present study, therefore, there was also comparisons of the pulmonary and hepatic echotextural characteristics. It was verified that hepatic tissue has a linear echogenicity during the last hours of gestation, similar to what has been reported in human foetuses (Maeda et al., 1999), although Banzato et al., (2017) reported liver echogenicity increased during the last gestational week in foetuses of dogs.

Computer-assisted analyses of pulmonary ultrasonographic images has the capacity to be a diagnostic tool for the non-invasive evaluation of lung foetal development in dogs, just as currently used in humans (Podobnik et al., 1996; Prakash et al., 2002). Not only can this method be used to enhance the understanding of gestational physiology of dogs, but it may also be utilised in clinical obstetrics of dogs, similar to what occurs with pregnant women for aiding in the diagnosis of preeclampsia, pulmonary immaturity, and abnormal foetal development (Podobnik et al., 1996; Prakash et al., 2002). Furthermore, although the digital images captured during the B-mode ultrasonographic examination are not analysed in real time, these are analysed with image analysis software within minutes of the acquisition, adding to this technique's value as a practical and applicable method.

The information obtained from the ARFI-elastographic technique may have both research and clinical relevance (Quarello et al., 
2016). The quantitative elastography confirmed that hepatic tissue has a greater stiffness than lung tissue (mean SWV $0.98 \pm 0.12$ and $0.84 \pm 0.11 \mathrm{~m} / \mathrm{s}$, respectively), and the values obtained in the present study may be used as reference ranges in future clinical studies. The values of the SWV of the foetal lung and liver tissues of dogs are similar to the corresponding human SWV values (mean $1.05 \pm 0.49$ and $1.09 \pm 0.24 \mathrm{~m} / \mathrm{s}$, respectively) during the second (18 weeks) and third trimester (35 weeks) of pregnancy and do not differ between the trimesters ( $P>0.05$ ), as reported by Zheng et al. (2016). In contrast to Zheng et al. (2016) and the findings in the present study, Quarello et al. (2016) evaluated the second half of baboon pregnancy every 4 weeks during a 9-month period, using real-time duplex B-mode elastography color-coded image techniques in which post-processing software sets the tissue stiffness in kilopascals. Nonetheless, even with the use of another technique, the lung stiffness behaviour of baboon foetuses during gestation was similar (quadratic relationship) to the quantitative echotexture evaluation results.

It has been suggested that changes in tissue echotexture may be associated with the characteristics of the tissue's elasticity (Ahmadi et al., 2013); however, the results of the present experiment did not confirm this relationship because there were no correlations among tissue elastographic and echotextural attributes. It is, however, important to acknowledge that the present results could have been affected by peristaltic movements occurring in pregnant bitches, variability in foetal organ depth, foetal movements, acoustic shadowing generated by foetal ribs, and the proportions of areas of interest evaluated. These limitations of both imaging techniques have previously been described by Quarello et al. (2015) and may impinge on the detection of relationships between echotextural and elastographic characteristics of foetal lungs and livers.

In summary, the echotextural and elastographic evaluation of the foetal liver and lungs of puppies during the last 5 days of gestation was feasible and did not cause any apparent alterations in maternal, foetal or neonatal viability. The pattern of changes in foetal pulmonary NPVs reflected the structural and functional changes that occur during the terminal stages of pre-natal lung development and can become a useful practical tool in clinical obstetrics. On the contrary, the shear wave velocity values for foetal lungs and liver remained constant during the last $120 \mathrm{~h}$ of gestation and there were no relationships with the echotexture of both organs. The present study provides validation for echotextural and elastographic analyses of foetal puppy tissues, which may be applied in future pathophysiological studies and clinical applications in different species of veterinary interest.

\section{Conflict of interest}

The authors declare that they have no competing interests.

\section{Acknowledgement}

The authors thank FAPESP for the research grantand young researcher award (processes 2012/16635-2; 2014/15117-3 and 2013/06443-1).

\section{References}

Adler, R.S., Rubin, J.M., Bland, P.H., Carson, P.L., 1990. Quantitative tissue motion analysis of digitized M-mode images: gestational differences of fetal lung. Ultrasound Med. Biol. 16, 561-569.

Ahmadi, B., Mirshahi, A., Giffin, J., Oliveira, M.E.F., Gaoa, L., Hahnel, A., Bartlewski, P.M., 2013. Preliminary assessment of the quantitative relationships between testicular tissue composition and ultrasonographic image attributes in the ram. Vet. J. 198, 282-285.

Banzato, T., Zovi, G., Milani, C., 2017. Estimation of fetal lung development using quantitative analysis of ultrasonographic images in normal canine pregnancy. Theriogenology 96, 158-163.

Beck, A.P.A., Araujo, E.J., Leslie, A.T.F.S., Camano, L., Moron, A.F., 2015. Assessment of fetal lung maturity by ultrasound: objective using gray-sacale histogram. J. Matern. Fetal. Neonatal. Med. 28, 617-622.

Benson, D.M., Waldroup, L.D., Kurtz, A.B., Rose, J.L., Rifkin, M.D., Goldberg, B.B., 1983. Ultrasonic tissue characterization of fetal lung, liver, and placenta for the purpose of assessing fetal maturity. J. Ultrasound Med. 2, 489-494.

Campbell, S., 1969. The prediction of fetal maturity by ultrasonic measurements of the biparietal diameter. J. Obstet. Gynecol. Br. Commonw. 7, 603-609.

Concannon, P.W., Whaley, S., Lein, D., Wissler, R., 1983. Canine gestation length: variation related to time of mating and fertile life of sperm. Am. J. Vet. Res. 44, $1819-1821$.

Cornfield, D.N., 2013. Acute respiratory distress syndrome in children: physiology and management. Curr. Opin. Pediatr. 25, 338-343.

Feliciano, M.A.R., Muzzi, L.A.L., Leite, C.A.L., Junqueira, M.A., 2007. Two-dimensional conventional, high resolution two-dimensional and three-dimensional ultrasonography in the evaluation of pregnant bitch. Arq. Bras. Med. Vet. Zootec. 59, 1333-1337.

Feliciano, M.A.R., Maronezi, M.C., Pavan, L., Castanheira, T.L., Simões, A.P.R., Carvalho, C.F., Canola, J.C., Vicente, W.R.R., 2014. ARFI elastography as complementary diagnostic method of mammary neoplasm in female dogs - preliminary results. J. Small Anim. Pract. 55, 500-508.

Feliciano, M.A.R., Maronezi, M.C., Crivellenti, L.Z., Crivellenti, S.B., Simões, A.P.R., Brito, M.B.S., Garcia, P.H.S., Vicente, W.R.R., 2015a. Acoustic radiation force impulse (ARFI) elastography of the spleen in healthy adult cats - a preliminary study. J. Small Anim. Pract. 56, $180-183$.

Feliciano, M.A.R., Maronezi, M.C., Simões, A.P.R., Uscategui, R.R., Maciel, G.S., Carvalho, C.F., Canola, J.C., Vicente, W.R.R., 2015b. Acoustic radiation force impulse elastography of prostate and testes of healthy dogs: preliminary results. J. Small Anim. Pract. 56, 320-324.

Feliciano, M.A.R., Garcia, P.H.S., Vicente, W.R.R., 2015c. Introdução à Ultrassonografia. In: Feliciano, M.A.R., Canola, J.C., Vicente, W.R.R. (Eds.), Diagnóstico por imagem em cães e gatos. MedVet, São Paulo, pp. 54-77.

Garcia, P.H.S., Feliciano, M.A.R., Carvalho, C.F., Crivellenti, L.Z., Maronezi, M.C., Almeida, V.T., Uscategui, R.R., Vicente, W.R.R., 2015. Acoustic radiation force impulse (ARFI) elastography of kidneys in healthy adult cats: preliminary results. J. Small Anim. Pract. 56, 505-509.

Giffin, J.L., Franks, S.E., Rodriguez-Sosa, J.R., Hahnel, A., Bartlewski, P.M., 2009. A study of morphological and haemodynamic determinants of testicular echotexture characteristics in the ram. Exp. Biol. Med. 234, 794-801.

Giffin, J.L., Bartlewski, P.M., Hahnel, A., 2014. Correlations among ultrasonographic and microscopic characteristics of prepubescent ram lamb testes. Exp. Biol. Med. 239, 1606-1618.

Holdsworth, A., Bradley, K., Birch, S., Browne, W.J., Barberet, V., 2014. Elastography of the normal canine liver, spleen and kidneys. Vet. Radiol. Ultrasound 55, $620-627$.

Jacomini, J.O., Cunha, G.N., Moreira, C.F., 2006. Use of the artificial insemination in Bulldogs bitches. Vet. Not. 12, $141-144$. 
Joshi, S., Kotecha, S., 2007. Lung growth and development. Early Hum. Dev. 83, 789-794.

Kim, S.M., Park, J.S., Norwitz, E.R., Hwang, E.J., Kang, H.S., Park, C.W., Jun, J.K., 2013. Acceleration time-to-ejection time ratio in fetal pulmonary artery predicts the development of neonatal respiratory distress syndrome: a prospective cohort study. Am. J. Perinatal. 30, 805-812.

Lourenço, M.L.G., Machado, L.H.A., 2013. Characteristics of fetal-neonatal transition period and physiological particularities of the neonate canine and feline. Rev. Bras. Reprod. Anim. 37, 303-308.

Maeda, K., Utsu, M., Yamamoto, N., Serizawa, M., 1999. Echogenicity of fetal lung and liver quantified by the grey-level histogram width. Ultrasound Med. Biol. 25, 201-208.

Maronezi, M.C., Feliciano, M.A.R., Crivellenti, L.Z., Simões, A.P.R., Bartlewski, P.M., Gill, I., Canola, J.C., Vicente, W.R.R., 2015. Acoustic radiation force impulse elastography of the spleen in healthy dogs of different ages. J. Small Anim. Pract. 56, 393-397.

Martin, J., Fanaroff, A., 2013. The preterm lung and airway: past, present, and future. Pediatr. Neonatol. 54, $228-234$.

Nicholas, D., Nassiri, D.K., Garbutt, P., Hill, C.R., 1986. Tissue characterization from ultrasound B-scan data. Ultrasound Med. Biol. 12 , 135-143.

Podobnik, M., Brayer, B., Ciglar, S., Duić, Z., Podgajski, M., 1996. Ultrasonic fetal and placental tissue characterization and lung maturity. Int. J. Gynaecol. Obstet. 54 $221-229$.

Prakash, K.N.B., Ramakrishnan, A.G., Suresh, S., Chow, T.W.P., 2002. Fetal lung maturity analysis using ultrasound image features. IEEE Trans. Inf. Technol. Biomed. 6, 38-45.

Quarello, E., Lacoste, R., Mancini, J., Dusseau, S.M., Gorincour, G., 2015. Feasibility and reproducibility of ShearWave (TM) elastography of fetal baboon organs. J. Prenat. Diagn. Ther. 35, 1112-1116.

Quarello, E., Lacosted, R., Mancinie, J., Melot-Dusseau, S., Gorincour, G., 2016. ShearWave elastography of fetal lungs in pregnant baboons. Diagn. Interv. Imaging 97, 605-610.

Rades, E., Bittar, R.E., Zugaib, M., 2004. Determinantes diretos do parto prematuro eletivo e os resultados neonatais. Rev. Bras. Ginecol. Obstet. 26, 655-662.

Serizawa, M., Maeda, K., 2010. Noninvasive fetal lung maturity prediction based on ultrasonic gray level histogram width. Ultrasound Med. Biol. 36, 1998-2003.

Shah, Y.G., Graham, and, 1986. Relationship of placental grade to fetal pulmonary maturity and respiratory distress syndrome. Am. J. Perinatol. 3, 53-55.

Silva, L.C.G., 2008. Parâmetros clínicos, hemogasométricos e radiográficos para avaliação respiratória de neonatos caninos nascidos em eutocia ou cesariana eletiva. Dissertação (mestrado). Universidade de São Paulo. Faculdade de Medicina Veterinária e Zootecnia, pp. $75 f$.

Silva, L.G., Vannucchi, G.P., Ucio, C.F., Rodrigues, J.A., Veiga, G.L., Vannucchi, C.I., 2015. The influence of the obstetrical condition on canine neonatal pulmonary functional competence. J. Vet. Emerg. Crit. Care San Antonio (San Antonio) 25, 725-730.

Sipriani, T.M., Grandi, F., Silva, L.C.G., Maiorka, P.C., Vannuchi, C.I., 2009. Pulmonary maturation in canine foetuses from early pregnacy to parturition. Reprod. Domest. Anim. 44, 137-140.

Socha, P., Rudowska, M., Janowski, T., 2012. Effectiveness of determining the parturition date in bitches using the ultrasonographic fetometry as compared to hormonal and cytological methods. Pol. J. Vet. Sci. 15, 447-453.

VanDuzer, T., Duggavathi, R., Murawski, M., Zieba, D.A., Sroka, P., Pawel, M., 2014. Correlations among antral follicular echotexture, apoptosis and expression of key steroidogenic enzymes in sheep. J. Reprod. Dev. 60, 476-482.

Yeager, A.E., Mohammed, H.O., Meyers-Wallen, V., Vannerson, L., Concannon, P.W., 1992. Ultrasonographic appearance of the uterus, placenta, fetus, and fetal membranes throughout accurately timed pregnancy in beagles. Am. J. Vet. Res. 53, 342-351.

Zheng, X.Z., Wu, J., Tan, X.Y., 2016. A novel approach to assessing fetal tissue stiffness using virtual touch tissue quantification. Med. Ultrason. 18, 70-74. 